\title{
Weight loss before conception: A systematic literature review
}

\author{
Elisabet Forsum ${ }^{*}$, Anne Lise Brantsæter², \\ Anna-Sigrid Olafsdottir ${ }^{3}$, Sjurdur F. Olsen ${ }^{4}$ and Inga Thorsdottir ${ }^{3}$ \\ 'Department of Clinical and Experimental Medicine, Linköping University, Linköping, Sweden; ${ }^{2}$ Division of \\ Environmental Medicine, Norwegian Institute of Public Health, Oslo, Norway; ${ }^{3}$ Unit for Nutrition Research, \\ Landspitali-University Hospital and University of Iceland, Reykjavik, Iceland; ${ }^{4}$ Maternal Nutrition Group, Division of \\ Epidemiology, Statens Serum Institute, Copenhagen, Denmark
}

\section{Abstract}

The prevalence of overweight and obesity in women has increased during the last decades. This is a serious concern since a high BMI before conception is an independent risk factor for many adverse outcomes of pregnancy. Therefore, dietary counseling, intended to stimulate weight loss in overweight and obese women prior to conception has recently been recommended. However, dieting with the purpose to lose weight may involve health risks for mother and offspring. We conducted a systematic literature review to identify papers investigating the effects of weight loss due to dietary interventions before conception. The objective of this study is to assess the effect of weight loss prior to conception in overweight or obese women on a number of health-related outcomes in mother and offspring using studies published between January 2000 and December 2011. Our first literature search produced 486 citations and, based on predefined eligibility criteria, 58 were selected and ordered in full text. Two group members read each paper. Fifteen studies were selected for quality assessment and two of them were considered appropriate for inclusion in evidence tables. A complementary search identified 168 citations with four papers being ordered in full text. The two selected studies provided data for overweight and obese women. One showed a positive effect of weight loss before pregnancy on the risk of gestational diabetes and one demonstrated a reduced risk for large-for-gestationalage infants in women with a BMI above 25 who lost weight before pregnancy. No study investigated the effect of weight loss due to a dietary intervention before conception. There is a lack of studies on overweight and obese women investigating the effect of dietary-induced weight loss prior to conception on health-related variables in mother and offspring. Such studies are probably lacking since they are difficult to conduct. Therefore, alternative strategies to control the body weight of girls and women of reproductive age are needed.

Keywords: gestational diabetes; large-for-gestational-age-infants; systematic review; weight loss before pregnancy

Received: 31 January 2012; Revised: 7 January 2013; Accepted: 30 January 20I3; Published: I3 March 2013

$\mathrm{T}$ he optimal body weight of pregnant women has been an issue of much debate over the years. It has long been recognized that underweight women tend to deliver small infants and a low birth weight is well known to be associated with increased mortality and morbidity in children (1). Recommendations regarding weight gain during pregnancy have also been given for a long time. For example, an American textbook on obstetrics (2) stated in 1966 that 'Excessive weight gain in pregnancy is highly undesirable for several reasons; it is essential to curtail the increment in gain to $12.5 \mathrm{~kg}$ at most or preferably $6.8 \mathrm{~kg}$. However, this policy of severe weight restriction during pregnancy was challenged already in the 1960s when it was realized that such a restriction is associated with an increased risk for low birth weight infants and consequently with several health problems in the offspring (3).

In 1990, the Institute of Medicine (IOM) of the National Academy of Science in the United States published a report on weight gain during pregnancy where such recommendations were based on the prepregnant BMI of the woman (4). It was recommended that lean and underweight women gain more weight than normal weight women and those were in turn recommended to gain more weight than overweight or obese women. The IOM report of 1990 (4) thus implemented 
the important fact that the preconceptional nutritional situation of a woman is important for her nutritional requirements during pregnancy.

The prevalence of overweight and obesity in women of reproductive age has increased considerably during the last decades. For example, in Sweden this figure increased from 25 to 36\% between 1992 and 2001 in pregnant women (5). This is a serious concern since a high BMI before pregnancy confers an increased risk of maternal and perinatal complications, including preeclampsia, gestational diabetes, caesarean delivery, largefor-gestational-age-infants, stillbirth and possibly an increased risk for overweight and obesity later in life in the offspring (5-7).

In 2009, IOM revisited their recommendations for pregnancy weight gain (Table 1) (6). The following statement was an important addition to their guidelines: 'All women should start pregnancy with a healthy body weight'. A BMI within the range of normal BMI values (18.5-24.9) is considered to be a healthy body weight. This recommendation was made since 'evidence from the literature is remarkably clear that prepregnancy BMI is an independent predictor of many adverse outcomes of pregnancy' $(6,7)$. In fact, it currently appears that, for obese women, prepregnancy BMI is more associated with an increased risk of preeclampsia, gestational diabetes mellitus, and the delivery of a large-for-gestational-age (LGA) infant than is gestational weight gain (8). The recent IOM report emphasized that the full implementation of their guidelines would mean: 'Offering preconceptional services, such as counseling on diet and physical activity as well as access to contraception, to all overweight or obese women to help them reach a healthy weight before conceiving' (6).

A recently published systematic review demonstrated positive effects for mother and offspring as a result of weight reductions during pregnancy (9). Furthermore, the recent IOM report (6) presents evidence that weight loss prior to conception is associated with improved reproductive outcomes for obese women undergoing bariatric surgery $(10,11)$. However, no studies regarding the effect of weight loss as a result of interventions including dietary manipulations and implemented prior to conception in overweight and/or obese women were

Table 1. Weight gain during pregnancy as recommended by the Institute of Medicine 2009 (6)

\begin{tabular}{lc}
\hline BMI $\left(\mathrm{kg} / \mathrm{m}^{2}\right)$ before conception & Recommended weight gain $(\mathrm{kg})$ \\
\hline$<18.5$ (underweight) & $12.5-18$ \\
$18.5-24.9$ (normal weight) & $11.5-16$ \\
$25.0-29.9$ (overweight) & $7-11.5$ \\
$>30.0$ (obesity) & $5-9$ \\
\hline
\end{tabular}

citied. This systematic literature review was conducted to identify published papers describing such studies.

\section{Research question}

The original research question was: Is there scientific evidence for positive health effects of weight loss prior to conception for overweight and obese women? Potential outcomes: weight and length of infants at birth, macrosomia, length of gestation/prematurity, malformations, stillbirth, childhood obesity/BMI, obstetric risk, preeclampsia, postpartum weight retention, gestational diabetes mellitus, hypertension, postpartum depression, lactation and lactation duration, infant growth. The strategy used to find literature relevant for this research question is shown in Table 2. Two databases (PubMed and Swe Med) were searched.

\section{Literature search}

The literature search is described in Fig. 1. The main search was conducted in November 2010, covering articles published between January 1, 2000, and July 15, 2010, and identifying 486 abstracts. These articles were read by three members of the pregnancy-and-lactationgroup. EF read all abstracts while IT and AS each read $50 \%$ of the abstracts. Thus, two persons read all abstracts. Abstracts were identified according to the following criteria: obesity and overweight before pregnancy (or between pregnancies) and change in body weight before pregnancy and any kind of health-related outcome including intervention trials ( $>1$ month) but excluding weight loss by surgery. In this way, 58 articles $(5,12-68)$ were identified and ordered in full text. Two members of the group read each of the 58 articles and if at least one member considered an article appropriate, it was selected for quality assessment. Review articles were excluded but

Table 2. Search strategy for 'Research Question'

('weight loss'[All Fields] OR 'weight management'[All Fields] OR 'weight counseling'[All Fields] OR 'pre-pregnancy body mass index'[All Fields] OR 'obesity intervention'[All Fields] OR 'following bariatric surgery'[All Fields]) AND ('pregnancy'[All Fields] OR 'fertilization'[All Fields] OR 'conception'[All Fields] OR 'infertility'[All Fields] OR 'fertility'[All Fields]) AND ('infant, newborn'[All Fields] OR 'fetal macrosomia'[All Fields] OR 'pregnancy'[All Fields] OR 'congenital abnormalities'[All Fields] OR 'stillbirth'[All Fields] OR 'pre-eclampsia'[All Fields] OR 'diabetes, gestational'[All Fields] OR 'hypertension, pregnancy-induced'[All Fields] OR 'depression, postpartum'[All Fields] OR 'lactation'[All Fields] OR 'breast feeding'[All Fields] OR 'abortion, spontaneous'[All Fields] OR 'bariatrics'[All Fields] OR 'infant, low birth weight'[All Fields] OR 'infant, very low birth weight'[All Fields] OR 'Obstetric Risk'[All Fields] OR 'Weight Management'[All Fields] OR 'Obesity Intervention'[All Fields]) AND ('2000/0I/0I'[PDat]: '2010/07/I5'[PDat]) AND ('Humans'[MH] OR Human*[TIAB]) 


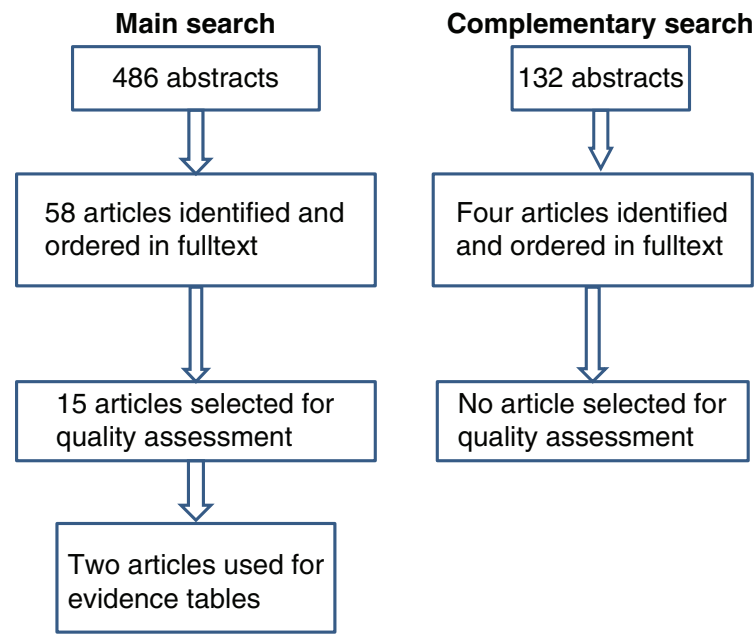

Fig. 1. Description of literature search, including main and complementary search.

otherwise inclusion criteria were the same as those used to identify abstracts. Reasons for excluding 43 of the articles (12-54) are shown in the appendix. Thus, this procedure resulted in 15 articles for quality assessment $(5,55-68)$.

\section{Final selection of articles and quality assessment}

The 15 articles were distributed between the five group members. Each member read 5-7 articles and two members, who also carried out the quality assessment of their articles, read all articles. Among the 15 selected articles $11(56,58,59,61-68)$ were found not to be relevant while four $(5,55,57,60)$ were considered relevant and of sufficient quality for inclusion in evidence tables. However, one of those (57) investigated the relationship between a reduction in BMI and a preterm birth but involved mainly low-to-normal-weight women and was thus not considered relevant for our review. Another (55) was a review emphasizing the lack of relevant studies for our particular research question. Thus, two studies, Villamor and Cnattingius (5) and Glazer et al. (60) were used in evidence tables providing data for two outcomes, i.e. risk of gestational diabetes and risk of LGA infants (Table 3). To assess and rate the quality of the included studies, we applied a three-category (A-B-C) grading system based on the NNR AMSTAR quality assessment tool (QAT).

\section{Complementary search}

At the end of January 2012, a complementary search (Fig. 1) was conducted covering the period between July 15, 2010, and the end of December 2011. The same search string and databases were used as in the main search. The complementary search resulted in 132 abstracts. These were read by two members of the group (EF and IT) and resulted in four articles (69-72) being ordered in full text. None of them were selected for QAT.

\section{Results}

Glazer et al. (60) provided evidence for a positive effect of weight loss (at least $10 \mathrm{lbs}$ or $4.54 \mathrm{~kg}$ ) between pregnancies on the risk of gestational diabetes during the subsequent pregnancy. Such an effect was not demonstrated by Villamor and Cnattingius (5) possibly because the women in their study weighed less and lost less weight than the women in the study by Glazer et al. (60) (Table 3). It is of interest to note, however, that the former study (5) demonstrated clearly that weight gain between pregnancies is associated with adverse health effects in mothers as well as in infants also when it occurs in normal-weight women. Furthermore, the study by Ehrlich et al. (70) confirms the findings by Glazer et al. (60) that weight loss between pregnancies, in obese and overweight women, has a positive effect on the risk for gestational diabetes in the subsequent pregnancy. Furthermore, the study by Villamor and Cnattingius (5) demonstrated a reduced risk for LGA infants in women with a BMI above 25 who lost weight equivalent to at least one BMI-unit before their next pregnancy (Table 3 ).

\section{Discussion}

As part of the review process, a referee alerted us about a paper by Getahun et al. (73) where changes, increases as well as decreases, in BMI during the first two pregnancies of more than 700,000 American women were analyzed in relation to LGA-births. This paper was not captured by our research question, probably since it was not presented as a paper focusing on weight loss. However, a decrease in BMI must be due to a loss of body weight. Getahun et al. (73) reported that obese women were at an increased risk for delivering LGA-infants. Furthermore, although the risk for delivering such an infant was attenuated if an obese woman lost weight between the two pregnancies, the risk was still higher than for normal weight women who maintained their body weight between their first two pregnancies.

Our research question did not include a statement requiring that weight loss should be the result of a dietary intervention. Nevertheless, it is evident from our review that studies regarding preconceptional dietary-based interventions aiming at weight reduction in overweight and obese women are currently lacking. Our literature search, including our complementary search, clearly shows that many women would benefit substantially from such a weight loss. Probable positive effects include improved reproductive outcome and improved health of mothers, for example reduced preeclampsia (71), as well as improved health of offspring. However, it is conceivable that preconceptional dietary-based interventions aiming at weight reduction in overweight and obese 
Table 3. Table for evidence grading: risk of gestational diabetes and risk of delivering a large-for-gestational-age infant

\begin{tabular}{|c|c|c|c|}
\hline Reference details & Glazer $\mathrm{N}$ et al. (60), USA & Villamor and Cnattingius (5), Sweden & Villamor and Cnattingius (5), Sweden \\
\hline Study design & Prospective cohort study & Prospective cohort study & Prospective cohort study \\
\hline $\begin{array}{l}\text { Population/subject } \\
\text { characteristics }\end{array}$ & $\begin{array}{l}\text { Obese women (heavier than } 200 \mathrm{lbs} \text { or } 90.7 \mathrm{~kg} \text { ) of mixed } \\
\text { ethnicity with } 2 \text { singleton births who were nondiabetic at } \\
\text { the first pregnancy }\end{array}$ & $\begin{array}{l}\text { Women in Sweden giving birth to two consecutive } \\
\text { singletons between } 1992 \text { and } 200 \text { I }\end{array}$ & $\begin{array}{l}\text { Women in Sweden giving birth to two consecutive } \\
\text { singletons between } 1992 \text { and } 2001\end{array}$ \\
\hline No of subjects analysed & 4,012 & 313 (from 151,025 ) for risk of gestational diabetes & $\begin{array}{l}2,350 \text { (from } 15 \mid, 025 \text { ) for risk of delivering a large-for- } \\
\text { gestational-age infant }\end{array}$ \\
\hline Outcome measures & Risk of gestational diabetes at the second pregnancy & Risk of gestational diabetes at the second pregnancy & $\begin{array}{l}\text { Risk of delivering a large-for gestational-age (LGA) } \\
\text { infant at the second pregnancy }\end{array}$ \\
\hline Exposure & $\begin{array}{l}\text { Prepregnancy weight at an index pregnancy minus the } \\
\text { corresponding weight at the previous pregnancy }\end{array}$ & $\begin{array}{l}\text { Difference between the two pregnancies with respect to } \\
\text { BMI recorded at the first antenatal visit }\end{array}$ & $\begin{array}{l}\text { Difference between the two pregnancies with respect } \\
\text { to BMI recorded at the first antenatal visit }\end{array}$ \\
\hline $\begin{array}{l}\text { Follow-up period, } \\
\text { drop-out rate }\end{array}$ & Nine-months follow-up, no drop-outs & Nine-months follow-up, no drop-outs & Nine-months follow-up, no drop-outs \\
\hline $\begin{array}{l}\text { Dietary assessment } \\
\text { method }\end{array}$ & No dietary assessment & No dietary assessment & No dietary assessment \\
\hline Results & $\begin{array}{l}\text { Women who lost at least } 10 \mathrm{lbs}(4.54 \mathrm{~kg}) \text { between pregnancies } \\
\text { had a decreased risk of gestational diabetes relative to women } \\
\text { who lost less weight during this period (relative risk }=0.63 \text {, } \\
95 \% \mathrm{Cl}, 0.38-1.02 \text { ) }\end{array}$ & $\begin{array}{l}\text { Overweight and obese women who decreased their } \\
\text { BMI more than one unit between pregnancies had no } \\
\text { significant reduction in the risk of gestational diabetes } \\
\text { (OR } 0.96,95 \% \mathrm{Cl}, 0.66-1.37 \text { ) }\end{array}$ & $\begin{array}{l}\text { Overweight and obese women who decreased their } \\
\text { BMI more than one BMI-unit between pregnancies } \\
\text { had a significant reduction in the risk of giving birth to } \\
\text { a LGA-infant (OR } 0.82,95 \% \mathrm{Cl}, 0.72-0.95 \text { ) }\end{array}$ \\
\hline $\begin{array}{l}\text { Confounders adjusted } \\
\text { for }\end{array}$ & Age and weight gain during each pregnancy & $\begin{array}{l}\text { Height, interpregnancy interval, age, country of origin, } \\
\text { years of education, year of delivery and smoking }\end{array}$ & $\begin{array}{l}\text { Height, interpregnancy interval, age, country of } \\
\text { origin, years of education, year of delivery and } \\
\text { smoking }\end{array}$ \\
\hline $\begin{array}{l}\text { Study quality and } \\
\text { relevance }\end{array}$ & $\begin{array}{l}\text { Study quality: B. The study is not quite relevant since there } \\
\text { is no information that the women received dietary advice } \\
\text { and we do not know why they lost weight }\end{array}$ & $\begin{array}{l}\text { Study quality: A. The study is not quite relevant since there } \\
\text { is no information that the women received dietary advice } \\
\text { and we do not know why they lost weight }\end{array}$ & $\begin{array}{l}\text { Study quality: A. The study is not quite relevant } \\
\text { since there is no information that the women } \\
\text { received dietary advice and we do not know why } \\
\text { they lost weight }\end{array}$ \\
\hline
\end{tabular}


women also may have harmful effects, for example risks of nutritional deficiencies (i.e. iron or folate) or disorders related to eating behavior. Another concern is pointed out by Zhang et al. (74) in a recent paper where the authors discuss evidence indicating that undernutrition as well as overnutrition, imposed during the periconceptional period, may both affect the offspring negatively. Thus, it was stressed in their paper that 'it is important to ensure that any dietary restriction interventions recommended for overweight and obese mothers are evidencebased to allow for an effective weighing up of the potential metabolic benefits and costs for the offspring'. The present paper shows that evidence-based strategies regarding how dietary interventions before conception should be carried out to be successful whilst simultaneously avoiding potentially harmful effects, are currently lacking. Although urgently needed such studies seem to be very difficult to carry out. The obvious reason for the lack of scientific evidence is a lack of data since recruiting women before conception is associated with practical problems. An alternative approach to the problem of overweight and obesity in reproductive women could be to develop public health strategies where serious efforts are made to counteract overweight and obesity in girls and young women. Additional efforts helping women to gain weight during pregnancy according to recommendations and to lose weight after delivery would be important parts of such a strategy. It should be emphasized, however, that efforts to control body weight should not occur at the prize of a nutritionally adequate dietary intake. Achieving these goals represents a difficult task but a task of considerable public health importance.

\section{Conflict of interest and funding}

The authors have not received any funding or benefits from industry or elsewhere to conduct this study.

\section{References}

1. World Health Organization. Feto-maternal nutrition and low birth weight. http://www.who.int/nutrition/topics/feto_maternal; 2011 [cited 3 May 2012].

2. Eastman N, Hellman L. Williams' obstetrics, 13th ed. New York: Appelton-Century-Crofts; 1966. p. 326.

3. Abrams B, Altman SL, Pickett KE. Pregnancy weight gain: still controversial. Am J Clin Nutr 2000; 71: 1233S-41S.

4. Institute of Medicine, National Research Council (1990). Nutrition during pregnancy, weight gain and nutrient supplements. Report of the subcommittee on nutritional status and weight gain during pregnancy. Subcommittee on dietary intake and nutrient supplements during pregnancy, Committee on nutritional status during pregnancy and lactation. Food and Nutrition Board. Washington, DC: National Academy Press.

5. Villamor E, Cnattingius S. Interpregnancy weight change and risk of adverse pregnancy outcomes: a population-based study. Lancet 2006; 368: 1164-70.

6. Institute of Medicine, National Research Council. Weight gain during pregnancy, re-examining the guidelines. In: Rasmussen
KM, Yaktine AL, eds. Washington, DC; The National Academy Press; 2009. pp. 1-13.

7. Johnson K, Posner SF, Biermann J, Cordero JF, Atrash HK, Parker CS, et al. Recommendations to improve preconception health and health care - United States. A Report of the CDC/ ATSDR Preconception Care Work Group and the Select Panel on Preconception Care. MMWR Recomm Rep 2006; 55: 1-23.

8. Nohr EA, Vaeth M, Baker JL, Sorenson TIA, Olsen J, Rasmussen KM. Combined associations of prepregnancy body mass index and gestational weight gain with the outcome of pregnancy. Am J Clin Nutr 2008; 87: 1750-9.

9. Thangaratinam S, Rogozinska E, Jolly K, Glinkowski S, Roseboom T, Tomlinson JW, et al. Effects of interventions in pregnancy on maternal weight and obstetric outcomes: metaanalysis of randomized evidence. BMJ 2012; 344: e2088. doi: 10.1136/bmj.e2088.

10. Guelinckx I, Devlieger R, Vansant G. Reproductive outcome after bariatric surgery: a critical review. Hum Reprod Update 2009; 15: 189-201.

11. Maggard MA, Yermilov I, Li Z, Maglione M, Newberry S, Suttorp M, et al. Pregnancy and fertility following bariatric surgery: a systematic review. JAMA 2008; 300: 2286-96.

12. Anonymous. Impact of physical activity during pregnancy and postpartum on chronic disease risk. Med Sci Sports Exerc 2006; 38: 989-1006.

13. Anonymous. Nutrition and reproduction in women. Hum Reprod Update 2006; 12: 193-200.

14. Anonymous. Theme: obesity \& overweight. Vårdfacket 2005; 29 : $1-24$.

15. Barger MK, Bidgood-Wilson M. Caring for a woman at high risk for type 2 diabetes. J Midwifery Women's Health 2006; 51: 222-6.

16. Bellver J, Busso C, Pellicer A, Remohi J, Simon C. Obesity and assisted reproductive technology outcomes. Reprod Biomed Online 2006; 12: 562-8.

17. Bitsko RH, Reefhuis J, Louik C, Werler M, Feldkamp ML, Waller DK, et al. Periconceptional use of weight loss products including ephedra and the association with birth defects. Birth Defects Res A Clin Mol Teratol 2008; 82: 553-62.

18. Bo S, Marchisio B, Volpiano M, Menato G, Pagano G. Maternal low birth weight and gestational hyperglycemia. Gynecol Endocrinol 2003; 17: 133-6.

19. Caughey AB. Obesity, weight loss, and pregnancy outcomes. Lancet 2006; 368: 1136-8.

20. Coitinho DC, Sichieri R, D’Aquino Benicio MH. Obesity and weight change related to parity and breast-feeding among parous women in Brazil. Public Health Nutr 2001; 4: 865-70.

21. Frederick IO, Rudra CB, Miller RS, Foster JC, Williams MA. Adult weight change, weight cycling, and prepregnancy obesity in relation to risk of preeclampsia. Epidemiology 2006; 17: 428-34.

22. Galtier FI, Raingeard I, Renard E, Boulot P, Bringer J. Optimizing the outcome of pregnancy in obese women: from pregestational to long-term management. Diabetes Metab 2008; 34: 19-25.

23. Gunderson EP, Abrams B, Selvin S. Does the pattern of postpartum weight change differ according to pregravid body size? Int J Obes Relat Metab Disord 2001; 25: 853-62.

24. Haugen M, Alexander J. Can linoleic acids in conjugated CLA products reduce overweight problems? Tidskrift for den Norske Laegeforening 2004; 124: 3051-4.

25. Hegaard HK, Petersson K, Hedegard M, Ottesen B, Dykes AK, Henriksen TB, et al. Sports and leisure-time physical activity in pregnancy and birth weight: a population-based study. Scand J Med Sci Sports 2010; 20: e96-e102. 
26. Jevitt CM. Weight management in gynecologic care. J Midwifery Women's Health 2005; 50: 427-30.

27. Johnson DB, Gerstein DE, Evans AE, Woodward-Lopez G. Preventing obesity: a life cycle perspective. J Am Diet Assoc 2006; 106: 97-102.

28. Jones EJ, Roche CC, Appel SJ. A review of the health beliefs and lifestyle behaviors of women with previous gestational diabetes. J Obstet Gynecol Neonatal Nurs 2009; 38: 516-26.

29. Keller C, Records K, Ainsworth B, Permana P, Coonrod DV. Interventions for weight management in postpartum women. J Obstet Gynecol Neonatal Nurs 2008; 37: 71-9.

30. Kuchenbecker WK, Ruifrok AE, Bolster JH, Heineman MJ, Hoek A. Subfertility in overweight women. Nederlands Tijdschrift voor Geneeskunde 2006; 150: 2479-83.

31. Kuhlmann AK, Dietz PM, Galavotti C, England LJ. Weightmanagement interventions for pregnant or postpartum women. Am J Prev Med 2008; 34: 523-8.

32. Lagiou P, Hsieh CC, Trichopoulos D, Xu B, Wuu J, Mucci L, et al. Birthweight differences between USA and China and their relevance to breast cancer aetiology. Int J Epidemiol 2003; 32: $193-8$.

33. Le Goff S, Ledee N, Bader G. Obesity and reproduction: a literature review. Gynecol Obstet Fertil 2008; 36: 543-50.

34. Lederman SA, Alfasi G, Deckelbaum RJ. Pregnancy-associated obesity in black women in New York City. Matern Child Health J 2002; 6: 37-42.

35. Ly CT, Diallo A, Simondon F, Simondon KB. Early short-term infant food supplementation, maternal weight loss and duration of breast-feeding: a randomised controlled trial in rural Senegal. Eur J Clin Nutr 2006; 60: 265-71.

36. Maloni JA, Alexander GR, Schluchter MD, Shah DM, Park S. Antepartum bed rest: maternal weight change and infant birth weight. Biol Res Nurs 2004; 5: 177-86.

37. McGuire W, Dyson L, Renfrew M. Maternal obesity: consequences for children, challenges for clinicians and carers. Semin Fetal Neonatal Med 2010; 15: 108-12.

38. Metwally M, Ledger WL, Li TC. Reproductive endocrinology and clinical aspects of obesity in women. Ann N Y Acad Sci 2008; 1127: 140-6

39. Morisset AS, St-Yves A, Veilette J, Weisnagel SJ, Tchernof A, Robitaille J. Prevention of gestational diabetes mellitus: a review of studies on weight management. Diabetes Metab Res Rev 2010; 26: 17-25.

40. Nelson SM, Fleming RF. The preconceptual contraception paradigm: obesity and infertility. Hum Reprod 2007; 22: 912-5.

41. Ostbye T, Krause KM, Lovelady CA, Morey MC, Bastian LA, Peterson BL, et al. Active Mothers Postpartum: a randomized controlled weight-loss intervention trial. Am J Prev Med 2009; 37: 173-80.

42. Pandey S, Bhattacharya S. Impact of obesity on gynecology. Women's Health 2010; 6: 107-17.

43. Rah JH, Shamim AA, Arju UT, Labrique AB, Klemm RD, Rashid $\mathrm{M}$, et al. Difference in ponderal growth and body composition among pregnant vs. never-pregnant adolescents varies by birth outcomes. Matern Child Nutr 2010; 6: 27-37.

44. Rooney BL, Schauberger CW. Excess pregnancy weight gain and long-term obesity: one decade later. Obstet Gynecol 2002; 100: $245-52$.

45. Rooney BL, Schauberger CW, Mathiason MA. Impact of perinatal weight change on long-term obesity and obesityrelated illnesses. Obstet Gynecol 2005; 106: 1349-56.

46. Saleh AM, Khalil HS. Review of nonsurgical and surgical treatment and the role of insulin-sensitizing agents in the management of infertile women with polycystic ovary syndrome. Acta Obstet Gynecol Scand 2004; 83: 614-21.
47. Seli E, Duleba AJ. Optimizing ovulation induction in women with polycystic ovary syndrome. Curr Opin Obstet Gynecol 2002; 14: 245-54.

48. Tema T. Prevalence and determinants of low birth weight in Ethiopia. East Afr Med J 2006; 83: 366-71.

49. Turhan NO, Seckin NC, Aybar F, Inegöl I. Assessment of glucose tolerance and pregnancy outcome of polycystic ovary patients. Int J Gynaecol Obstet 2003; 81: 163-8.

50. Walker LO, Sterling BS, Timmerman GM. Retention of pregnancy-related weight in the early postpartum period: implications for women's health services. J Obstet Gynecol Neonatal Nurs 2005; 34: 418-27.

51. Vallianatos H, Brennand EA, Raine K, Stephen Q, Petawabano B, Dannenbaum D, et al. Beliefs and practices of First Nation women about weight gain during pregnancy and lactation: implications for women's health. Can J Nurs Res 2006; 38: $102-19$.

52. Weissgerber TL, Wolfe LA, Davies GA, Mottola MF. Exercise in the prevention and treatment of maternal-fetal disease: a review of the literature. Appl Physiol Nutr Metab 2006; 31: $661-74$.

53. Winkvist A, Rasmussen KM, Lissner L. Associations between reproduction and maternal body weight: examining the component parts of a full reproductive cycle. Eur J Clin Nutr 2003; 57: 114-27.

54. Yogev Y, Langer O. Recurrence of gestational diabetes: pregnancy outcome and birth weight diversity. J Mater-Fetal Neonatal Med 2004; 15: 56-60.

55. Birdsall KM, Vyas S, Khazaezadeh N, Oteng-Ntim E. Maternal obesity: a review of interventions. Int J Clin Pract 2009; 63: 494-507.

56. Callaway LK, O`Callaghan MJ, McIntyre HD. Barriers to addressing overweight and obesity before conception. Med J Aust 2009; 191: 425-8.

57. Chen A, Klebaoff MA, Basso O. Prepregnancy body mass index change between pregnancies and preterm birth in the following pregnancy. Paediatr Perinat Epidemiol 2009; 23: 207-15.

58. Crosignani PG, Colombo M, Vegetti W, Somigliana E, Gesatti A, Ragni G. Overweight and obese anovulatory patients with polycystic ovaries: parallel improvements in anthropometric indices, ovarian physiology and fertility rate induced by diet. Hum Reprod 2003; 18: 1928-32.

59. Davis E, Olson C. Obesity in pregnancy. Prim Care 2009; 36: $341-56$

60. Glazer NL, Hendrickson AF, Schellenbaum GD, Mueller BA. Weight change and the risk of gestational diabetes in obese women. Epidemiol 2004; 15: 733-7.

61. Linné Y, Rössner S. Easy to remain overweight after pregnancy. Läkartidningen 2003; 100: 4091-5.

62. Moran LJ, Noakes M, Clifton PM, Tomlinson L, Galletly C, Norman RJ. Dietary composition in restoring reproductive and metabolic physiology in overweight women with polycystic ovary syndrome. J Clin Endocrinol Metab 2003; 88: 812-9.

63. Moran LJ, Norman RJ. The obese patient with infertility: a practical approach to diagnosis and treatment. Nutr Clin Care 2002; 5: 290-7.

64. Mutsaerts MA, Groen H, Bogt NC, Bolster JH, Land JA, Bemelmans WJ, et al. The LIFESTYLE study: costs and effects of a structured lifestyle program in overweight and obese subfertile women to reduce the need for fertility treatment and improve reproductive outcome. A randomised controlled trial. BMC Women's Health 2010; 10: 22.

65. Olsen SF, Dragsted LO, Hansen HS, Michaelsen KF, Milman $\mathrm{N}$, Nielsen MJ, et al. The scientific basis of current official dietary recommendations in relation to pregnancy. Ugeskrift for Laeger 2005; 167: 2782-4. 
66. Paramsothy P, Lin YS, Kernic MA, Foster-Schubert KE. Interpregnancy weight gain and caesarean delivery risk in women with a history of gestational diabetes. Obstet Gynecol 2009; 113: 817-23.

67. Raatikainen K, Heiskanen N, Heinonen S. Transition from overweight to obesity worsens pregnancy outcome in a BMIdependent manner. Obesity (Silver Spring) 2006; 14: 165-71.

68. Rodriguez A, Miettunen J, Henriksen TB, Olsen J, Taanila A, Ebeling $\mathrm{H}$, et al. Maternal adiposity prior to pregnancy is associated with ADHD symptoms in offspring: evidence from three prospective pregnancy cohorts. Int J Obes 2008; 32: 550-7.

69. Diouf I, Charles MA, Thiebaugeorges O, Forhan A, Kaminski $\mathrm{M}$, Heude B, et al. Maternal weight change before pregnancy in relation to birthweight and risks of adverse pregnancy outcomes. Eur J Epidemiol 2011; 26: 789-96.

70. Ehrlich SF, Hedderson MM, Feng J, Davenport ER, Gunderson EP, Ferrara A. Change in body mass index between pregnancies and the risk of gestational diabetes in a second pregnancy. Obstet Gynecol 2011; 117: 1323-30.

71. Mostello D, Chang JJ, Allen J, Luehr L, Shyken J, Leet T. Recurrent preeclampsia. The effect of weight change between pregnancies. Obstet Gynecol 2010; 116: 667-72.
72. Whiteman VE, Rao K, Duan J, Alio A, Marthy PJ, Salihu HM. Changes in prepregnancy body mass index between pregnancies and risk of preterm phenotypes Am J Perinatol 2011; 28: 67-74.

73. Getahun D, Ananth CV, Peltier MR, Salihu HM, Scorza WE. Changes in prepregnancy body mass index between the first and second pregnancies and risk of large-for-gestational birth. Am J Obstet Gynecol 2007; 196: 530.e1-8.

74. Zhang S, Rattanatray L, Morrison JL, Nicholas LM, Lie S, McMillen IC. Maternal obesity and the early origins of childhood obesity: weighing up the benefits and costs of maternal weight loss in the periconceptional period for the offspring. Exp Diabetes Res 2011; 2011: 585749. doi: 10.1155/2011/585749.

*Elisabet Forsum

Department of clinical and experimental medicine

Linköping University

SE-58। 85 Linköping

Sweden

Email: elisabet.forsum@liu.se

Appendix

Papers ordered in full text but not included in the systematic literature review. The reason for exclusion is also given

\begin{tabular}{|c|c|}
\hline Papers excluded & Reason for exclusion \\
\hline Anonymous (12) & Not relevant for research question \\
\hline Anonymous (I3) & Not relevant for research question \\
\hline Anonymous (14) & Not relevant for research question \\
\hline Barger et al. (15) & Not relevant for research question \\
\hline Bellver et al. (16) & Not relevant for research question \\
\hline Bitsko et al. (17) & Focus on safety of weight loss products, Not relevant \\
\hline Bo et al. (I8) & Study of maternal low birth weight, Not relevant \\
\hline Caughey et al. (19) & Not a research paper, Not relevant \\
\hline Coitinho et al. (20) & Not relevant for research question \\
\hline Frederick et al. (2I) & Deals with weight gain, not weight loss, Not relevant for research question \\
\hline Galtier et al. (22) & Not relevant for research question \\
\hline Gunderson et al. (23) & Not relevant for research question \\
\hline Haugen et al. (24) & Not relevant for research question \\
\hline Hegaard et al. (25) & Not relevant for research question \\
\hline Jevitt (26) & Not relevant for research question \\
\hline Johnson et al. (27) & Not relevant for research question \\
\hline Jones et al. (28) & Not relevant for research question \\
\hline Keller et al. (29) & Not relevant for research question \\
\hline Kuchenbecker et al. (30) & Review, Not main topic, Not relevant \\
\hline Kuhlmann et al. (3I) & Wrong topic, Not relevant \\
\hline Lagiou et al. (32) & Wrong topic, Not relevant for research question \\
\hline Le Goff et al. (33) & Review \\
\hline Lederman et al. (34) & Wrong topic, Not to the point, Not relevant for research question \\
\hline Ly et al. (35) & Wrong topic, Not relevant \\
\hline Maloni et al. (36) & Wrong topic, Not relevant \\
\hline McGuire et al. (37) & Wrong topic, Not relevant \\
\hline Metwally et al. (38) & Wrong topic, Not relevant \\
\hline Morisset et al. (39) & Not relevant for research question \\
\hline Nelson et al. (40) & No appropriate outcome, Review \\
\hline
\end{tabular}


Appendix (Continued)

Papers excluded

Reason for exclusion

Ostbye et al. (4I)

Pandey et al. (42)

Rah et al. (43)

Rooney et al. (44)

Rooney et al. (45)

Saleh et al. (46)

Seli et al. (47)

Tema (48)

Turhan et al. (49)

Walker et al. (50)

Vallianatos et al. (5I)

Weissgerber et al. (52)

Winkvist et al. (53)

Yogev et al. (54)
Not appropriate for research question

No appropriate outcome, Review

Not appropriate for research question

Not appropriate for research question

Not appropriate for research question, Not relevant

Not appropriate for research question, Not relevant

Not appropriate for research question, Review, Not relevant

About low birth weight, not relevant for research question

Not relevant for research question

Not relevant for research question

About weight gain, not weight loss, Not relevant

Not relevant for research question, Review

Not relevant for research question, Review

Not relevant for research question 